AperTO - Archivio Istituzionale Open Access dell'Università di Torino

\title{
Pharmacokinetics of linezolid during extracorporeal membrane oxygenation
}

\section{This is the author's manuscript}

Original Citation:

\section{Availability:}

This version is available http://hdl.handle.net/2318/22206

since

Published version:

DOI:10.1016/j.ijantimicag.2013.01.016

Terms of use:

Open Access

Anyone can freely access the full text of works made available as "Open Access". Works made available under a Creative Commons license can be used according to the terms and conditions of said license. Use of all other works requires consent of the right holder (author or publisher) if not exempted from copyright protection by the applicable law. 


\section{Pharmacokinetics Of Linezolid}

\section{During Extracorporeal Membrane Oxygenation}

Sir,

The extracorporeal membrane oxygenation (ECMO) is increasingly used in the critical setting for patients with respiratory failure and there is a growing body of knowledge describing the associated variations in plasma concentrations of drugs, including antibiotics, due to drug adsorption on the different components of the ECMO circuit. Currently, a multicentre study is ongoing to confirm if the standard antibiotic dosing in adult patients may still be considered appropriate [1]. Linezolid (LNZ) is extensively used in patients with pneumonia in critical care because of its strong activity against Staphylococcus aureus and its high pulmonary penetration, but there are no data on LNZ pharmacokinetics during ECMO [2]. Here we report the main pharmacokinetic parameters in three critically ill patients on ECMO treated with LNZ.

Patient 1 was a 61-year-old man, with a body mass index (BMI) of 24, who underwent lung transplantation because of chronic obstructive pulmonary disease and was treated with LNZ for pneumonia caused by meticillin-resistant $S$. aureus (MRSA) with a LNZ minimum inhibitory concentration (MIC) of $1 \mathrm{mg} / \mathrm{L}$. Patient 2 was a 40-year-old woman $(\mathrm{BMI}=18)$ with cystic fibrosis $(\mathrm{CF})$ who was on the transplant list, empirically treated with LNZ and previously colonised by MRSA. Patient 3 was a 32-year-old woman $(\mathrm{BMI}=31)$ with severe pneumonia caused by influenza H1N1 and pulmonary bacterial superinfection by meticillin-susceptible $S$. aureus (LNZ MIC 
$=4 \mathrm{mg} / \mathrm{L}$ ) isolated from bronchoalveolar lavage, previously treated with oxacillin that was stopped because of jaundice.

Plasmatic concentrations of LNZ were studied during ECMO, after informed consent was signed, at steady-state with the standard dosage of $600 \mathrm{mg}$ every $12 \mathrm{~h}$ intravenously by $1-\mathrm{h}$ infusion. The area under the curve (AUC) of daily $\left(A \cup C_{0-24}\right)$ plasma concentrations of LNZ was calculated with blood samples collected before (time 0 ) and 1, 2.5, 4, 6 and $8 \mathrm{~h}$ after the intravenous administration. Minimum plasma concentration $\left(C_{\mathrm{min}}\right)$ is defined as the concentration before the administration and the maximum plasma concentration $\left(C_{\max }\right)$ is defined as the concentration at the end of the infusion. LNZ was determined in plasma by ultra performance liquid chromatography-photodiode array (UPLC-PDA) method. Pharmacokinetic data were studied using Kinetica software (Thermo Scientific, Waltham, MA) and $\mathrm{AUC}_{0-24}$ was calculated as $\mathrm{AUC}_{0-24}=2 \times \mathrm{AUC}_{0-12}$ [3]. In Table 1 the main LNZ pharmacokinetic parameters are reported, such as $C_{\max }, C_{\min }, \mathrm{AUC}_{0-}$ 24, half-life $\left(t_{1 / 2}\right)$, clearance $(\mathrm{CL})$, time above the MIC $(t>\mathrm{MIC})$ and volume of distribution $\left(V_{\mathrm{d}}\right)$; we also reported in Table 1 the LNZ pharmacokinetic parameters calculated with S. aureus MICs corresponding to 1, 2 and $4 \mathrm{mg} / \mathrm{L}$ for Patients 1, 2 and 3 , respectively.

These results show that the calculated pharmacokinetic parameters of LNZ during ECMO are satisfactory when the MRSA MIC is $\leq 1 \mathrm{mg} / \mathrm{L}$, with $\mathrm{AUC}_{0-24} / \mathrm{MIC}$ ratio $\geq 80$ in all patients $[3,4]$. Only patient 3 did not display a full 24-hour plasma concentration above the $\mathrm{MIC}=1 \mathrm{mg} / \mathrm{L}$, with $t>\mathrm{MIC}$ corresponding to $66 \%$ of the 
dosing interval. The rate of achievement of pharmacological parameters decreases for all patients with MIC values $>1 \mathrm{mg} / \mathrm{L}$, as detailed in Table 1 , for both $\mathrm{AUC}_{0-24} / \mathrm{MIC}$ ratios and $t>$ MIC.

This is the first report of LNZ plasma concentrations in patients treated with ECMO, where we also included calculated data for different MICs to provide a reference for future patients. According to our data, even if limited, pharmacokinetic targets are not achieved with standard dosage of LNZ when the MRSA MIC is $>1 \mathrm{mg} / \mathrm{L}$.

Notwithstanding the limited sample size and heterogeneity of patients, including lung transplant, CF and high BMI, we conclude that plasma pharmacodynamic targets are easily achieved only when the $S$. aureus MIC is $\leq 1 \mathrm{mg} / \mathrm{L}$. According to our results, patients infected by $S$. aureus with MICs $>1 \mathrm{mg} / \mathrm{L}$ on ECMO should be considered, pending future confirmation, at considerable risk of inadequate pharmacokinetic coverage. Prolonged or continuous infusion of LNZ might be needed in critically ill patients to increase $\mathrm{AUC}_{0-24} / \mathrm{MIC}$ ratios or $\mathrm{t}>\mathrm{MIC}$, as well as increased dosage or combination therapy.

Funding: This study was funded by ASPIRE 2010 ("Pharmacokinetic Of Linezolid In The ICU") to the Department of Anesthesia and Critical Care, S. Giovanni Battista Molinette Hospital, Turin, Italy.

Competing interests: FGDR and GDP have been speakers or advisory board members for Pfizer; VMR has received funding from Pfizer. All other Authors declare no competing interests. 
Ethical approval: Ethical approval was given by the Ethical Committee of the

S.Giovanni Battista - Molinette Hospital in Turin, Italy.

\section{References}

[1] Shekar K, Roberts JA, Welch S, Buscher H, Rudham S, Burrows F, et al. ASAP ECMO: Antibiotic, Sedative and Analgesic Pharmacokinetics during Extracorporeal Membrane Oxygenation: a multi-centre study to optimise drug therapy during ECMO. BMC Anesthesiol 2012;12:29.

[2] Boselli E, Breilh D, Rimmelé T, Djabarouti S, Toutain J, Chassard D, et al. Pharmacokinetics and intrapulmonary concentrations of linezolid administered to critically ill patients with ventilator-associated pneumonia. Crit Care Med 2005;33:1529-33.

[3] Dong H, Wang X, Dong Y, Lei J, Li H, You H, et al. Clinical pharmacokinetic/pharmacodynamic profile of linezolid in severely ill intensive care unit patients. Int J Antimicrob Agents 2011;38:296-300.

[4] Pea F, Furlanut M, Cojutti P, Cristini F, Zamparini E, Franceschi L, et al. Therapeutic drug monitoring of linezolid: a retrospective monocentric analysis. Antimicrob Agents Chemother 2010;54:4605-10.

Francesco G. De Rosa ${ }^{a, *}$ Silvia Corcione ${ }^{a}$ Lorena Baietto ${ }^{a}$ Alessandra Ariaudo ${ }^{a}$ Giovanni Di Perri ${ }^{\text {a }}$ 
V. Marco Ranieri ${ }^{\text {b }}$ Antonio D'Avolio ${ }^{a}$

${ }^{a}$ Department of Medical Sciences, Infectious Diseases Clinic at Amedeo di Savoia Hospital, University of Turin, Corso Svizzera 164, 10149 Torino, Italy

${ }^{\mathrm{b}}$ Department of Anesthesia and Critical Care Medicine, City of Health and Science, Ospedale S. Giovanni Battista-Molinette, University of Turin, Italy * Corresponding author. Tel.: +39 0114393979 fax: +390114393882

E-mail address: francescogiuseppe.derosa@unito.it (F.G. De Rosa) 


\section{Table 1.}

Pharmacokinetic parameters of linezolid for patients 1,2 and 3, and calculated data for Staphylococcus aureus minimum inhibitory concentrations (MICs) of 1, 2 and 4 $\mathrm{mg} / \mathrm{L}$.

\section{Patient 1 Patient 2 Patient 3}

\begin{tabular}{llll}
\hline Pharmacokinetic parameters & & & \\
$C_{\max }(\mathrm{mg} / \mathrm{L})$ & 15.67 & 18.51 & 15.61 \\
$C_{\min }(\mathrm{mg} / \mathrm{L})$ & 4.25 & 0.47 & 0.43 \\
$\mathrm{AUC}_{0-24}(\mathrm{mg} \mathrm{h} / \mathrm{L})$ & 212.58 & 165.65 & 100.59 \\
$\mathrm{CL}(\mathrm{L} / \mathrm{h})$ & 5.65 & 7.24 & 13.35 \\
$V_{\mathrm{d}}(\mathrm{L})$ & 49.7 & 17.6 & 46.77 \\
$t_{1 / 2}(\mathrm{~h})$ & 6.10 & 1.68 & 2.20
\end{tabular}

Calculated data

$\begin{array}{llll}\text { AUC }_{0-24} / \mathrm{MIC}(\mathrm{MIC}=1) & 212.58 & 165.65 & 100.58 \\ \mathrm{AUC}_{0-24} / \mathrm{MIC}(\mathrm{MIC}=2) & 106.29 & 82.83 & 50.30 \\ \mathrm{AUC}_{0-24} / \mathrm{MIC}(\mathrm{MIC}=4) & 53.14 & 41.41 & 25.15 \\ \text { t>MIC (MIC = 1) (\% over 12 h) } & 100 & 100 & 66 \\ \text { t>MIC (MIC = 2) (\% over 12 h) } & 100 & 75 & 41 \\ \text { t>MIC (MIC = 4) (\% over 12 h) } & 100 & 58.3 & 30\end{array}$

$C_{\max }$, maximum plasma concentration; $C_{\min }$, minimum plasma concentration; $\mathrm{AUC}_{0-}$ 24: area under the curve of plasma daily concentrations; $C L$, clearance; $V_{d}$, volume of distribution; $t_{1 / 2}$, half-life; $t>M I C$, time of plasma concentrations above the MIC. 